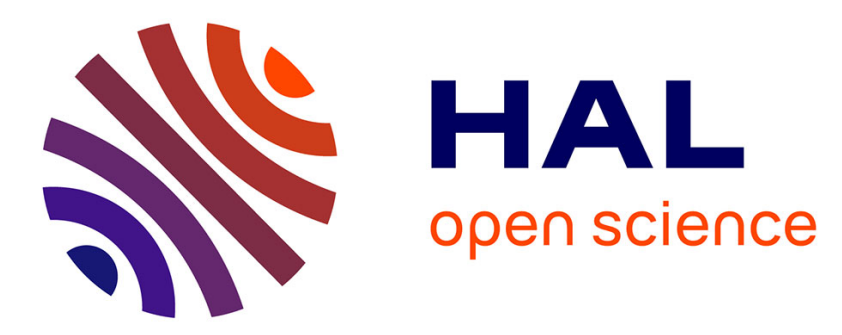

\title{
Turning principles into practice in Alzheimer's disease
}

James Lindesay, Roger Bullock, Hugo Daniels, Murat Emre, Hans Förstl, Lutz Frölich, Tomasz Gabryelewicz, Pablo Martínez-Lage, Andreas Monsch, Magda Tsolaki, et al.

\section{- To cite this version:}

James Lindesay, Roger Bullock, Hugo Daniels, Murat Emre, Hans Förstl, et al.. Turning principles into practice in Alzheimer's disease. International Journal of Clinical Practice, 2010, 64 (9), pp.1198. 10.1111/j.1742-1241.2010.02417.x . hal-00552658

\section{HAL Id: hal-00552658 https://hal.science/hal-00552658}

Submitted on 6 Jan 2011

HAL is a multi-disciplinary open access archive for the deposit and dissemination of scientific research documents, whether they are published or not. The documents may come from teaching and research institutions in France or abroad, or from public or private research centers.
L'archive ouverte pluridisciplinaire HAL, est destinée au dépôt et à la diffusion de documents scientifiques de niveau recherche, publiés ou non, émanant des établissements d'enseignement et de recherche français ou étrangers, des laboratoires publics ou privés. 


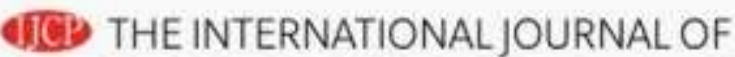 CLINICAL PRACTICE}

\section{Turning principles into practice in Alzheimer's disease}

\begin{tabular}{|c|c|}
\hline Journal: & International Journal of Clinical Practice \\
\hline Manuscript ID: & IJCP-12-09-0773.FT10.R1 \\
\hline Manuscript Type: & Perspective \\
\hline $\begin{array}{r}\text { Date Submitted by the } \\
\text { Author: }\end{array}$ & $11-$ Mar-2010 \\
\hline Complete List of Authors: & $\begin{array}{l}\text { Lindesay, James; Leicester General Hospital, Psychiatry for the } \\
\text { Elderly } \\
\text { Bullock, Roger; Kingshill Research Centre, Victoria Hospital } \\
\text { Daniels, Hugo; Ziekenhuis Oost-Limburg, Memory Clinic, } \\
\text { Department of Geriatrics } \\
\text { Emre, Murat; Istanbul University, Department of Neurology, } \\
\text { Behavioural Neurology and Movement Disorders Unit, Istanbul } \\
\text { Faculty of Medicine } \\
\text { Förstl, Hans; University of Heidelberg } \\
\text { Frölich, Lutz; University of Heidelberg, Department of Geriatric } \\
\text { Psychiatry, Central Institute of Mental Health, Medical Faculty } \\
\text { Mannheim } \\
\text { Gabryelewicz, Tomasz; Mossakowski Medical Research Centre, } \\
\text { Polish Academy of Sciences, Department of Neurodegenerative } \\
\text { Disorders } \\
\text { Martínez-Lage, Pablo; Fundación Alzheimer Centre Educational } \\
\text { Monsch, Andreas; University Hospital, University of Basel, Memory } \\
\text { Clinic, Department of Geriatrics } \\
\text { Tsolaki, Magda; Aristotle University of Thessaloniki } \\
\text { van Laar, Teus; University Medical Centre }\end{array}$ \\
\hline Specialty area: & \\
\hline
\end{tabular}

\section{scholaroNE" \\ Manuscript Central}




\section{Turning principles into practice in Alzheimer's disease}

James Lindesay $^{1^{\star}}$, Roger Bullock ${ }^{2^{\star}}$, Hugo Daniels ${ }^{3}$, Murat Emre ${ }^{4}$, Hans Förstl ${ }^{5}$, Lutz Frölich $^{6}$, Tomasz Gabryelewicz ${ }^{7}$, Pablo Martínez-Lage ${ }^{8}$, Andreas U. Monsch ${ }^{9}$, Magda Tsolaki $^{10}$, Teus van Laar $^{11}$

${ }^{1}$ Leicester General Hospital, Leicester, UK

${ }^{2}$ Kingshill Research Centre, Swindon, UK

${ }^{3}$ Memory Clinic, Department of Geriatrics, Ziekenhuis Oost-Limburg, Genk, Belgium

${ }^{4}$ Department of Neurology, Behavioural Neurology and Movement Disorders Unit, Istanbul Faculty of Medicine, Istanbul University, Istanbul, Turkey

${ }^{5}$ University of Heidelberg, Mannheim, Germany

${ }^{6}$ Department of Geriatric Psychiatry, Central Institute of Mental Health, Medical

Faculty Mannheim, University of Heidelberg, Mannheim, Germany

${ }^{7}$ Department of Neurodegenerative Disorders, Mossakowski Medical Research

Centre, Polish Academy of Sciences, Warsaw, Poland

${ }^{8}$ Fundación Alzheimer Centre Educational, Barcelona, Spain

${ }^{9}$ Memory Clinic, Department of Geriatrics, University Hospital, University of Basel, Basel, Switzerland

${ }^{10}$ Aristotle University of Thessaloniki, Thessaloniki, Greece

${ }^{11}$ University Medical Centre, Groningen, The Netherlands

\section{*Corresponding authors:}

Professor James Lindesay

Psychiatry for the Elderly

Leicester General Hospital

Leicester, LE5 4PW

UK

Tel: $+44(0) 1162588161$

Fax: +44 (0) 1162731115

Email: jebl1@leicester.ac.uk
Dr Roger Bullock

Kingshill Research Centre

Victoria Hospital

Okus Road, Swindon

SN1 9PU, UK

Tel: +44 (0) 1793437501

Fax: +44 (0) 1793437636

Email: Roger.Bullock@awp.nhs.uk 
Disclosures: All authors have acted as paid consultants for Novartis. The authors did not receive remuneration for the production of this manuscript. James Lindesay has received speaker and consultancy fees from companies involved in the manufacturing and marketing of drugs for dementia - Eisai, Pfizer, Shire, Janssen-Cilag. Roger Bullock acts as an advisor, receives research grants and has been a speaker for several companies working in the field of dementia. Hugo Daniels has no conflicts to disclose other than his involvement in NEURONET-Dementia, a Novartis-sponsored initiative. Murat Emre acts as an advisor, receives research grants and has been a speaker for several companies working in the field of dementia. Hans Förstl has received project funding, consultancy fees and speaker's honoraria from all major pharmaceutical companies including Astra-Zeneca, Bayer, Eisai, Elan-Wyeth, Eli-Lilly, GE-Healthcare, Janssen-Cilag, Lundbeck, Merz, Novartis and Pfizer. Lutz Frölich has received research funding, consultancy fees or speech honoraria from companies involved in the manufacture and marketing of drugs for Alzheimer's disease including: Allergan, AstraZeneca, Cephalon, Eisai, Elan/Weyth, Eli Lilly, GE Health Care, Janssen-Cilag, Lundbeck, Merz Pharma, Myriad, Neurochem, Novartis, Pfizer and ScheringPlough. Tomasz Gabryelewicz acts as an advisor, receives research grants and has been a speaker for several companies working in the field of dementia. Pablo Martínez-Lage has received honoraria as a member of advisory boards from Pfizer, Novartis, Lundbeck and Janssen-Cilag, and speech honoraria for the participation in symposia and other educational activities from Pfizer, Novartis, Lundbeck, Janssen-Cilag, Esteve, and AndromacoGrunenthal. Andreas Monsch has received research funding, consultancy fees or speech honoraria from companies involved in the manufacture and marketing of drugs for Alzheimer's disease including: BayerHealthCare, Janssen-Cilag, Lundbeck, Merz Pharma, Novartis, Pfizer, and Vifor. Magda Tsolaki has no other conflicts of interest to declare. Teus van Laar has received lecture fees, consultancy fees and research funding from Novartis, and research funding from Janssen Cilag. 


\begin{abstract}
The prevalence of dementia is reaching epidemic proportions globally, but there remain a number of issues that prevent people with dementia, their families and caregivers, from taking control of their condition. In 2008, Alzheimer's Disease International (ADI) launched a Global Alzheimer's Disease Charter, which comprises six principles that underscore the urgency for a more ambitious approach to diagnosis, treatment and care. This review highlights some of the most important aspects and challenges of dementia diagnosis and treatment. These issues are reviewed in light of the six principles of the recent ADI Charter: promoting dementia awareness and understanding; respecting human rights; recognizing the key role of families and caregivers; providing access to health and social care; stressing the importance of optimal diagnosis and treatment; and preventing dementia through improvements in public health. The authors continue to hope that, one day, a cure for Alzheimer's disease will be found. Meanwhile, healthcare professionals need to unite in rising to the challenge of managing all cases of dementia, using the tools available to us now to work toward improved patient care.
\end{abstract}

\title{
How did you gather, select and analyse the information you considered in your
} review? The concept and content of this review is based on discussions that took place during a meeting of European dementia specialists in March 2009. The aspects of dementia diagnosis and treatment they considered of greatest importance in light of the key principles of the recent Alzheimer Disease International Global Charter are reviewed.

What is the take-home message for the clinician? Individuals with dementia, their families and carers have a human right to a more ambitious, proactive approach to diagnosis, treatment and care. All healthcare professionals are encouraged to rise to the challenge of managing all cases of dementia, using the tools available today, to work toward improved patient care. 


\section{Introduction}

Alzheimer's disease is recognized as one of the main causes of the dementia syndrome, and one of the most burdensome conditions of later life (1). Growing recognition that the prevalence of dementia is reaching epidemic proportions globally has caused the profile of this progressive, debilitating condition to rise as a health and social care priority. A wealth of literature exists, including various clinical practice guidelines, offering evidence-based recommendations for early diagnosis and management of dementia. However, from the general public through to specialist care, there remain a number of issues that prevent people with dementia, their families and caregivers from taking control of their condition.

In the absence of a cure for Alzheimer's disease, symptomatic treatments play a key role in dementia management. However, the majority of people with Alzheimer's disease still remain untreated $(60 \%$ or more in most European countries), and of those who are prescribed treatment, many receive doses that are lower than recommended (2). Despite evidence that individuals with Alzheimer's disease who take their medication as prescribed for longer have a greater chance of slowing symptom progression (3), treatment compliance in this patient group is known to be poor (4). Perceived lack of effectiveness, associated side effects, forgetfulness and complexity of multiple drug regimens are factors that may lead to poor compliance and treatment discontinuation in elderly subjects with dementia (4).

In 2008, Alzheimer's Disease International (ADI) launched a Global Alzheimer's Disease Charter (5). The primary goal of this 'Call for Action' campaign was to address the challenges that dementia presents. Their Charter comprises six principles that underscore the urgency for a more ambitious approach to diagnosis, treatment and care (Table 1).

In this review, members of the Neurology in EUROpe educational NETwork in Dementia (NEURONET-Dementia; comprising a group of European physicians) highlight their perception of the most important aspects of dementia diagnosis and treatment, in light of the principles of the recent ADI Charter. 


\section{Promote dementia awareness and understanding}

Worldwide there are 4.6 million new cases of dementia reported each year, which is equivalent to one new case of dementia every 7 seconds (1). As prevalence increases exponentially with advancing age (6), rates are set to escalate further as the elderly population continues to grow. Currently, most people with dementia live in developing countries $(60 \%)(1)$, where improvements in public health have already extended the average life span. As initiatives to improve factors such as cardiovascular health are implemented in developing countries, average life span is expected to be further extended. A major consequence of this unquestionable success of increased life expectancy is that the life span "without disability" has not been proportionally prolonged. Life expectancy may have reached the age of 80 to 85 years in many countries, but the life span without disability remains in the low 70s. Regional projected rates of increase in dementia prevalence reflect this, with 1-fold and 3-fold increases expected between 2001 and 2040 in developed and developing countries, respectively (1). Dementia is one of the main causes of disability in later life (7), so is one of the most costly of medical conditions from a health and social care perspective (8). Any actions that might minimize the impact of this burdensome disease warrant urgent attention.

Early recognition, diagnosis and intervention are important to ensure best possible quality of life for people with dementia, their families and caregivers. Epidemiological studies have shown that a large proportion of patients with dementia remain undetected, undiagnosed and subsequently untreated. Only $60 \%$ of people who meet the diagnostic criteria receive a formal diagnosis of dementia (9). There are many factors, mostly related to attitudes and limited awareness of both the general population and physicians, that contribute to late or missed diagnosis. Key factors include: lack of awareness or understanding of dementia and attitudes towards dementia (e.g., stigma, denial or fear) (10). Lack of knowledge, or the belief that symptoms of dementia are just a normal part of the aging process, is common (11). The wrong generalized perception that there are no effective 
treatments for $A D$ and other dementias may mislead patients and relatives not to seek early medical advice. There is also a 'protective' reluctance to diagnose a patient with dementia because of perceived negative attitudes and preconception about the disease. Some physicians may feel uncertain about the diagnosis in the very early stages and may prefer to delay the diagnosis until the dementia syndrome is more advanced.

A number of physicians still use the term "senile dementia" giving patients and caregivers the false impression that dementia is a natural consequence of aging. Moreover, patients and relatives may misinterpret the diagnosis and perceive that "senile dementia" has a more benign prognosis than Alzheimer's disease. Once complications such as behavioural symptoms, domestic or car accidents, financial difficulties, and many others start to arise, a precious amount of time has already been lost without any pharmacological or non-pharmacological intervention. Alzheimer's disease is not a part of normal aging - it is an insidious condition that needs to be managed in a sympathetic but proactive way. Better awareness and understanding of the condition by the general public and healthcare providers is an imperative step in achieving this. Early diagnosis can help patients and families to take control of their condition. It gives them the choice to start treatment as soon as the physician thinks it is appropriate, and provides an opportunity to plan for the future (e.g., making a will, legal affairs, and decisions about care). Actions are needed to promote better health education of the general public concerning recognition of the early symptoms of dementia and awareness of the actual benefits of early pharmacological and nonpharmacological interventions. Primary care physicians and specialists need training programmes and improved easy-to-use diagnostic tools to detect, diagnose and treat dementia patients early. Health authorities, media, health professionals and family associations should coordinate efforts in the promotion and development of these actions. Celebrities and public personalities sharing their dementia diagnosis experiences with the general population may also play a significant role. 


\section{Respect human rights}

Another principle of the ADI Global Charter is that, "A person with dementia continues to be a person of worth and dignity, and deserving the same respect as any other human being" (5). For as long as individuals with mild and moderate dementia are capable and maintain a level of self-awareness, they should be kept informed and be included in decisions relating to their daily life (e.g., treatment and care options) (5). In a recent survey, more than $90 \%$ of people with dementia indicated that they wanted to be more involved in decision-making. Although some physicians tend to withhold disclosure of a dementia diagnosis to avoid associated distress, just as with cancer, timely provision of this information is vital if appropriate action is to be taken. Most patients with dementia would prefer to receive full disclosure of their diagnosis (12), allowing them and their families to take control of their disease and plan for the future. Effective disclosure of a dementia diagnosis includes providing adequate information and treatment options (non-pharmacological and pharmacological) (13). Ongoing social support in the form of regular follow-up visits and contact with local associations are also helpful ways to help the adjustment to a diagnosis of dementia.

As dementia advances, decision-making responsibilities are necessarily taken on by the family or caregiver. In cases where an individual is deemed mentally incapable of activities such as driving or managing finances, legislation is required to protect their rights. Even so, challenges may still arise in the medical management of these patients, who are unable to provide informed consent or make difficult choices about their own care. For example, it is often difficult to consider the appropriate use of surgical interventions in patients with severe dementia. Another difficult decision that typically falls to family members is the use of tube-feeding at advanced stages of the disease - how does the patient's human right to be provided with sufficient nutrients for life sit with the patient's right to refuse food if they do not want to eat? Specific guidance differs by country; specialist physicians 
should be aware of their local legislations relating to assessment of capacity, consent to treatment and research, disclosure of diagnosis, and advance directives (14).

The ultimate objective must be to define broad, uniform European guidance to secure the human rights of people with dementia. For example, there remains a wide variation across Europe in the availability, quality and approaches to end-of-life and palliative care. Cases of assisted suicide feature largely in the press in countries such as the UK (15), the arguments for maintaining the value of human life, versus those for assisted suicide in cases of unbearable suffering, are frequently passionate and often emotional. There is a need for an objective and compassionate debate between healthcare providers, politicians, patient groups and religious representatives, with the objective of developing sensible, broadly acceptable guidelines and legislation on this sensitive topic.

Another ethical issue that may give rise to mixed feelings is that of genetic testing. The rapid progression of genetic research in the second half of the $20^{\text {th }}$ century led to a concern that ethics could not 'keep up' with technology (16). For example, the ability to test for predictive genes could provide medical actuaries with information that could impact an individual's ability to obtain health insurance. In countries such as the USA, where healthcare provision is largely dependent on the ability to obtain insurance, this could have a huge financial impact on many people, and might deprive some of vital healthcare in their advanced years.

Dementia needs focused research and resourcing. Worldwide input into research and resources, in particular for preventive strategies, into other disease areas (e.g. cardiovascular health) has seen cardiac-related deaths decline dramatically over the past decades. There continues to be heated debate about the use of human embryonic stem cells for research purposes (17). Until these issues are resolved, ideally with a Europeanwide resolution applying to all member states, differences between countries are likely to continue to lead to confusion and discord. 


\section{Recognize the key role of families and caregivers}

Dementia does not only affect the person with the disease; it also has a direct impact on close family members $(18,19)$. Between 67 and $95 \%$ of people with Alzheimer's disease are cared for at home (20). The role of a caregiver is multifaceted, from assistance with practical care activities, such as dressing, cooking or toileting, to administering and managing medications. Consequently, late-stage dementia is one of few conditions where it is often a caregiver, rather than the patient, who makes all disease- and treatment-related decisions. This has important implications for patient-caregiver-physician interactions, and for practical aspects of care such as treatment compliance and adherence (4).

As dementia progresses, caregiver workload and responsibilities escalate, often resulting in increased physical and emotional stress (21). By easing some of the symptoms of dementia, current treatments can help to improve quality of life not only for the patient, but also for the caregiver $(22,23)$. Yet, medication management is a known contributor to caregiver workload and stress (24). In an ADI commissioned survey of persons with Alzheimer's disease and their caregivers, factors highlighted as being most important to family members and other caregivers centred on treatment management. Caregivers and family members indicated that they wanted better control of the patient's symptoms, fewer bothersome side effects, medications in a form that makes them easier to take, a dosing regimen that is easier to comply with, and to know that the patient's medications were being taken as directed (13). Any improvement in medication management from a caregiver perspective has the potential to favourably impact patient outcomes (25).

The provision of adequate support and advocacy for families and caregivers of a person with dementia is essential. Healthcare providers remain the primary source of dementia information, and are the gateway to local Alzheimer associations (which are well established Europe-wide) and support groups (13). Utility of dementia organizations varies across countries. Alzheimer Europe is a non-profit organization that aims to improve the care and treatment of Alzheimer patients through intensive collaboration between its member 
associations. In the long term, Alzheimer Europe is striving to become the co-ordination and information centre for all organizations working in this specific field, such as day-care centres, sitting services, training centres for professionals and related organizations (20). Although many caregivers are aware of their national dementia organizations, accessibility (lack of time and inconvenient location) appears to be a common barrier (13). Nevertheless, local Alzheimer associations and support groups offer valuable guidance for minimizing the impact of dementia and preserving quality of life. As clearly stated in the ADI Global Charter, "The family caregivers of a person with dementia should have their needs assessed and provided for and should be enabled to take an active role in this process" (5). Healthcare providers play a crucial role in introducing caregivers and family members to the support networks available to them. Additional sources of information and support include: the internet, telephone help-lines, print media, and friends and family members.

An understanding of the nature and causes of the clinical symptoms of dementia can lead to better care. In addition, encouraging a 'humanitude' approach to care - specific ways of touching, looking at, speaking to, and positioning of oneself that acknowledge the person behind the patient - can promote positive outcomes for the person with dementia and the caregiver (26).

\section{Provide access to health and social care}

One of the underlying principles of the ADI Global Charter is that people with dementia require up-to-date information and access to coordinated medical, psychological, rehabilitative and welfare services (5). Anyone thought to have dementia deserves prompt medical assessment; those diagnosed with dementia require ongoing care and treatment orientated to maximising their quality of life.

Training and resources are required to ensure health and social care professionals and family caregivers are equipped to enable early assessment, diagnosis, appropriate care, and access to optimal treatment. 
In particular, primary care services must be responsive to the needs of people with dementia. In many countries across Europe, approved treatments for dementia can be initiated only by a specialist. Primary care physicians have a central role ensuring that patients presenting with any signs or symptoms of dementia are managed appropriately. Increasing their awareness of dementia through educational initiatives is paramount to ensuring that patients with possible dementia are referred to a specialist physician at the earliest opportunity.

One approach to this may be to introduce screening programmes for dementia (similar to those routinely used for prostate or breast cancer), which should be tailored to focus on individuals who have a high risk for development dementia. However, until the case for dementia screening becomes better evidence-based and more widely accepted, efforts to promote timely detection should focus on removing barriers to diagnosis, and encouraging referrals to specialist care.

\section{Stress the importance of optimal diagnosis and treatment}

International Alzheimer's Associations and practice guidelines encourage timely detection and diagnosis of dementia, and subsequent treatment initiation (14). The importance and advantages of early diagnosis have already been discussed. The European Federation of Neurological Societies (EFNS) has recently published recommendations on the diagnosis of dementia (14). Clinical diagnosis should be based on agreed criteria (e.g. DSM-IV/NINCDSADRDA for Alzheimer's disease (27); Consortium criteria for dementia with Lewy bodies (28); NINDS-AIREN for vascular dementia (29)). Extending these criteria, the EFNS guidelines state that neuroimaging is now the most important investigation in the work-up of dementia to aid in differential diagnosis and management decisions (14). Structural brain imaging (computer tomography or magnetic resonance imaging [MRI]) should be used in the evaluation of every patient suspected of dementia. Figure 1 shows structural MRI in Alzheimer's disease, where hippocampal, medial-temporal and whole brain atrophy, with 
resulting ventricular enlargement are key features. Other techniques may be used if uncertainty remains after clinical and structural work-up. For example, single photon emission computed tomography (SPECT) provides a measurement of regional cerebral blood flow, which is reflective of neuronal activity. Bilateral temporal, parietal and posterior cingular hypoperfusion tends to be apparent in Alzheimer's disease (Figure 2). Fluorodeoxyglucose positron emission tomography (FDG-PET) imaging, a more refined investigational technique, can also be used to measure brain metabolism, and in Alzheimer's disease it will typically show bilateral temporoparietal hypometabolism (Figure 3); however, this has yet to be made clinically widely available. In addition, growing evidence supports the added diagnostic value of specific cerebrospinal fluid biomarkers (e.g. amyloid- $\beta$, total tau and phospho-tau) for evaluation of patients with atypical presentations of Alzheimer's disease (27).

The EFNS also recommends that medical history (including co-morbidities) should be collected from patients, and supplemented by an independent informant when possible (14). Assessments of cognitive performance, activities of daily living (ADLs), behavioural and psychological symptoms are central to the diagnosis of dementia and should be performed in all patients (14). A general neurological and physical examination should also be performed, and screening blood tests should be used to identify potential reversible causes and aggravators of cognitive impairment (e.g. metabolic, infectious and toxic conditions), and any physical co-morbidities (14).

Once diagnosed with Alzheimer's disease, all patients and their caregivers should be offered the opportunity to benefit from non-pharmacological and pharmacological therapies. Non-pharmacological options include 'cognitive training' exercises. Typically, these focus on specific domains of cognitive functioning, though more general cognitively-mediated domains of functioning (e.g. ADLs, instrumental ADLs, social skills and behavioural disturbances) can also be targeted (30). It involves guided practice on a set of standard tasks designed to reflect particular cognitive functions, such as memory, attention, or problem-solving ('executive functions'). The underlying assumption is that practice has the 
potential to improve or at least maintain functioning in the given domain, and that any effects of practice will generalize beyond the immediate training context. A meta-analysis of 17 controlled studies identified suggests that patients with Alzheimer's disease may derive some cognitive and functional benefits from cognitive training (30). Restorative cognitive training strategies demonstrate larger effect sizes than compensatory strategies. The largest effect sizes were seen in the domains of learning, memory, executive functioning, ADLs, general cognition, depression, and general functioning.

Among pharmacological options (Table 2), the available treatments for Alzheimer's disease offer symptomatic improvements with meaningful benefits. Cholinesterase inhibitors (rivastigmine, donepezil and galantamine) are widely approved for the treatment of mild to moderate Alzheimer's disease (14) (Table 2). As a class, these agents can offer benefits in three main affected areas, the ABCs of Alzheimer's disease: ADLs; behaviour; and cognitive function (31-33). Recent guidance from the Committee for Medicinal Products for Human Use (CHMP) acknowledge the particular importance of ADL as an outcome criterion for any future clinical trials in AD. For the purpose of drug approval, they suggest that two primary outcomes should be used, assessing cognition and ADLs (34). While cognitive dysfunction is the hallmark of $A D$, and can be measured objectively, ADL assessment is useful to evaluate the meaningful impact of a treatment on everyday functioning. For the demonstration of patient-related clinical benefits, outcome parameters related to ADL function, behavioural symptoms or quality of life should be followed. Furthermore, clinical endpoints such as functional worsening or nursing home placement might be useful, despite their methodological difficulties $(34,35)$.

In principle, initiation of treatment in early (mild to moderate) stages of dementia has the greatest potential to improve long-term outcomes, by delaying symptomatic decline while the cognitive reserve is still relatively preserved (36). The benefits of early cholinergic treatment are suggestive, but not proven, across separate open-label extension studies of rivastigmine (oral and transdermal) $(37,38)$, donepezil $(39)$ and galantamine $(40)$ in patients with Alzheimer's disease. In each of these trials, patients who received placebo initially in the 
core double-blind phase (i.e. a delayed treatment start) did not appear to "catch up" with those who received treatment for the entire study period. The EFNS guidelines recommend treatment with cholinesterase inhibitors be considered at the time of diagnosis in patients with Alzheimer's disease, taking into account expected therapeutic benefits and potential safety issues (14). This guidance is also being followed at the national level. For example, the UK Department of Health National Dementia Strategy, which includes a summary of National Institute for Clinical Excellence (NICE) and Social Care Institute for Excellence (SCIE) evidence for dementia services, specifies 'good quality early diagnosis and intervention for all' as one of their 17 objectives (41). However, in the absence of firm evidence of cost-effectiveness, the NICE treatment guidelines do not yet support cholinesterase inhibitor therapy in mild AD. Treatment at later disease stages is also important. Neocortical cholinergic deficits still progress in the disease course (42), and patients with more advanced Alzheimer's disease, who may have greater cholinergic deficits, have been shown to derive particularly strong benefits from cholinesterase inhibitor therapy $(43,44)$.

Advanced Alzheimer's disease is typically associated with the emergence of behavioural and psychotic problems. Cholinesterase inhibitors have demonstrated some efficacy in behavioural symptoms (45), although their role in more severely disturbed patients may be limited (46). This is important because in elderly dementia populations the safety of antipsychotic use has been called into question in recent years. Trials have shown an increased likelihood of serious cerebrovascular adverse events such as stroke and transient ischemic attack (TIA) in elderly patients taking some atypical antipsychotic agents (47). Effective use of cholinesterase inhibitors can delay the onset and decrease the severity of neuropsychiatric symptoms in dementia, and may reduce the requirement for antipsychotic and other psychotropic medications $(48,49)$. In elderly subjects with behavioural and psychotic symptoms of dementia, cholinesterase inhibition may provide a more appropriate therapeutic option than conventional antipsychotic or neuroleptic agents (47). 
It is important that adequate doses of cholinesterase inhibitors are prescribed. Although statistically significant differences have been demonstrated, the benefits demonstrated in clinical trials of these agents may be below clinically-relevant thresholds (50). However, a study based on standard clinical practice in Italy showed that $65 \%$ of patients taking cholinesterase inhibitors - which exhibit dose-response relationships - are taking suboptimal doses (51), at least partially explaining a lack of response in some patients. Physicians should encourage patients to reach target therapeutic doses of these agents, in order to provide optimal benefits. If patients are unable to reach target therapeutic doses due to associated side effects, slower dose escalation, taking oral agents with food, or the use of a transdermal patch therapy may improve tolerability (52). A careful clinical search for comorbid medical conditions, which may induce a rapid cognition decline, is also warranted before depriving patients of the potential benefits of treatment altogether (53).

For patients already receiving target recommended doses but still not responding to treatment, switching to an alternative cholinesterase inhibitor may provide benefits (53). For example, in one open-label French study, among 382 AD patients who had previously failed to benefit from treatment with donepezil, over half subsequently responded to treatment after switching to rivastigmine, as assessed using a global function scale (54). In severe Alzheimer's disease, the addition of memantine to a cholinesterase inhibitor regimen may also offer some symptom relief. In a trial of 404 patients with moderate to severe AD, who were already receiving stable doses of donepezil, the addition of memantine resulted in a 0.9-point improvement on the Severe Impairment Battery, while patients receiving placebo (on top of donepezil) declined by 2.5 points (55).

Unfortunately, adherence to Alzheimer's disease therapies is notoriously low. Alzheimer's disease is a chronic disease, yet the average pharmacological treatment duration is estimated to be a mere $4-5$ months (56). Ensuring patients stay on any medication long-term is difficult, but among the Alzheimer's disease population (including caregivers) non-compliance due to forgetfulness and difficulties coping with multiple medication regimens is particularly common (4). Some patients or caregivers voluntarily 
discontinue treatment due to a perceived lack of efficacy, and it is important to always communicate realistic expectations. For example, the disease will inevitably progress despite treatment, and while treatment effects with current therapies are modest they may impact on cognition as well as behaviour. With long-term treatment, a less than expected decline despite further clinical worsening may be regarded as a clinical benefit. Patients and caregivers who understand the potential benefits and limitations of treatment may be more likely to stay on treatment for longer. Families of patients with Alzheimer's disease are continually seeking the most promising treatment for their loved ones, and a better commitment to ensuring treatment compliance and adherence may be expected if they understand fully all issues surrounding the effects of treatment.

\section{Prevent dementia through improvements in public health}

National initiatives in other areas of medicine have had a huge impact. For example, public health efforts in cardiovascular disease have resulted in significant reductions in cardiovascular morbidity and mortality. Survival rates from cancer have markedly increased in the past decade alone. Screening and rigorous medical treatment have played a major role in these achievements, proving that prevention and cure are possible, provided a coordinated effort is made. Public and professional information campaigns are fundamental to improving current levels of awareness, knowledge, and attitudes towards dementia. Broad educational programmes are needed to raise awareness among the public, primary care professionals, and specialist physicians that dementia is a common but manageable condition that warrants not only early diagnosis and treatment, but also risk reduction strategies.

There are several factors related to lifestyle, such as physical and psychosocial activity, smoking, alcohol drinking or nutrition, as well as (cardio)vascular factors, all of which modify the risk of dementia and Alzheimer's disease $(57,58)$. These factors may be influenced by interventions: there is good evidence to treat systolic hypertension (> $140 \mathrm{~mm}$ 
$\mathrm{Hg}$ ) at any time of life. In addition to reducing the risk of stroke, the incidence of dementia may be reduced. Cross-sectional studies consistently show a reduced occurrence of dementia among statin users (59). However, results of ongoing interventional statin trials need to be positive before we can recommend statin use for dementia prevention. There is good evidence to avoid the use of oestrogen, alone or in combination with progesterone, for reducing the risk of dementia (60). Although there are many reasons for treating type 2 diabetes mellitus, hyperlipidaemia and hyperhomocysteinaemia, there is insufficient evidence to recommend for or against treatment of these conditions for the purpose of reducing the risk of dementia (61). Although obesity and especially central obesity in midlife increases risk of dementia independent of diabetes and cardiovascular co-morbidities; there is no interventional study on reduced risk after weight loss. There is some evidence that natural or high intake of vitamins $B, C$ and $E$ from food decreases dementia risk (62); however, there is insufficient evidence to recommend for or against supplementation with vitamins $B, C$ and $E$ for the prevention of dementia. Adherence to the Mediterranean diet may affect not only risk for Alzheimer disease, but also subsequent disease course (63). Frequent consumption of fruits and vegetables, fish, and omega-3 rich oils may decrease the risk of dementia and Alzheimer disease. Avoidance of tobacco can be recommended. There are potential advantages of moderate consumption of wine (specific doses cannot be stated, although effects on diseases other than dementia suggest beneficial associations with 1-2 glasses per day for men, and up to 1 drink for women).

Regular exercise, both physical and mental, as well as adequate social interaction, may reduce the risk of dementia, and can therefore be recommended in midlife and later age groups (64). Alzheimer's disease in particular may be negatively associated with diversity of activities and intensity of intellectual activities, and positively associated with psychosocial inactivity. A potential protective effect of the psychosocial network on dementia has been demonstrated in several studies $(65,66)$. Leisure activities with all three components physical, mental, and social - seem to have the most beneficial impact. Therefore, physical, mental and social stimulation should be integrated into a common life-style although, at 
present, no clear evidence from intervention trials exists on the effectiveness in reducing the risk of dementia or Alzheimer disease.

The interaction of depression with dementia is complicated. Depression can be a prodromal symptom, a first sign of dementia, the result of dementia or can be an independent risk factor. There is robust evidence that individuals with a history of depression have a higher risk of dementia in later life. Although depression may be modifiable, there is no evidence that interventions on depression reduce the elevated risk for dementia (67).

To translate such preventive approaches into intervention studies and potentially to implement them into medical practice, large-scale dementia strategies are required. A number of national dementia strategies already exist across Europe. For example, the Department of Health in the UK published their National Dementia Strategy in February 2009 (68). This 5-year plan is based on 17 interlinked objectives ranging from a public information campaign to effective national regional support for implementation of the strategy (Table 3), supported by $£ 150$ million extra funding. The UK strategy has four key themes: improving awareness; early and better diagnosis; improved quality of care; and delivering the strategy. A dementia strategy with similar key research and care issues has been formulated within the presidential plan against dementia in France. In Germany, one of the goals of the longterm national strategy for Alzheimer's disease is to coordinate and condense research efforts nationwide. Therefore, the German government has decided to establish a new German Centre for Neurodegenerative diseases (DZNE) within the Helmholtz Society. The DZNE will collate competences and perform research on prevention, diagnosis, therapies in an interdisciplinary manner, and also coordinate health care and nursing research. In addition to the core centre in Bonn, six partner institutions have been selected across Germany. A budget of up to $€ 50$ million per year is envisaged.

The implementation of national dementia strategies around the world is a step in the right direction, but further investment in, and dialogue about, dementia management and research is required. 


\section{Discussion}

The diagnosis and management of dementia urgently need attention from national and global healthcare providers and funders, in order to address the forthcoming dementia epidemic (1). The ADI Global Charter provides the basis for such initiatives (5), and it is now the responsibility of healthcare providers and governments across the world to start implementing the necessary tasks to prevent a crisis. Lobbying groups will play an essential role in encouraging the allocation of necessary government funds for these initiatives, and in raising awareness among the public that dementia is not a 'normal' part of aging. Greater efforts must be made to raise global awareness and remove the stigma of dementia, and to ensure that human rights are protected for people with dementing illnesses. Early diagnosis is an essential first step in allowing people with dementia, and their families, to take control of the condition and prepare for the future.

Healthcare providers have a responsibility to provide the most effective treatments available to patients, with the aim of delaying the progression of dementia for as long as possible. Three cholinesterase inhibitors and the N-methyl-D-aspartic acid (NMDA) receptor antagonist memantine are currently widely available, with proven symptomatic benefits when administered correctly $(14,45)$.

Healthcare professionals also act as a gateway to local associations and networks for families and caregivers of patients with dementia. These groups provide emotional and practical support and assistance, and have the potential to significantly enhance the quality of life and well-being of both the patient and the caregiver.

The role of healthcare professionals should be (and already is, in many countries) outlined in national dementia strategies. Those strategies need to be realistic and accessible to all those who could benefit from them. In particular, in many countries across Europe, since the primary care practitioner is the first point of contact, educational programmes to inform primary care providers about optimal management of people presenting with 
symptoms of dementia is essential. In most cases, currently, this will comprise referral to a specialist physician. If shown to be effective, disease management programmes built into primary care practices and offering standard operating procedures might be desirable.

In conclusion, we would encourage our peers to lobby for greater national investment in research and public health programmes relating to dementia. We endorse the principles of the ADI Global Charter, and encourage the proactive screening, diagnosis and management of dementia. We continue to hope that, one day, a cure for Alzheimer's disease will be found. Meanwhile, we ask all healthcare professionals to proactively rise to the challenge of managing all cases of dementia, using the tools available to us now to work toward a healthier and happier - if inevitably older - Europe.

\section{Author contributions}

All authors are members of the NEURONET-Dementia faculty, and they participated in a Novartis-sponsored NEURONET-Dementia meeting held on $15^{\text {th }}$ March 2009, where they devised the concept and content of this review. All authors contributed to the content, drafting, critical revision and approval of this review article.

\section{Acknowledgements}

The Neurology in EUROpe educational NETwork in Dementia (NEURONET-Dementia) initiative is sponsored by Novartis Pharma AG. Novartis sponsored Alpha-Plus Medical Communications Ltd (UK) to provide writing and editorial assistance with the production of this review, under the guidance of the authors. 


\section{References}

1. Ferri CP, Prince M, Brayne $C$ et al. Global prevalence of dementia: a Delphi consensus study. Lancet. 2005; 366: 2112-7.

2. Waldemar G, Phung KT, Burns A et al. Access to diagnostic evaluation and treatment for dementia in Europe. Int J Geriatr Psychiatry. 2007; 22: 47-54.

3. Small GW, Kaufer D, Mendiondo MS et al. Cognitive performance in Alzheimer's disease patients receiving rivastigmine for up to 5 years. Int J Clin Pract. 2005; 59: 473-7.

4. Small G, Dubois B. A review of compliance to treatment in Alzheimer's disease: potential benefits of a transdermal patch Curr Med Res Opin. 2007; 23: 2705-13.

5. Alzheimer's Disease International. Global Alzheimer's Disease Charter. http://wwwglobalcharterorg/; 2008.

6. Rocca WA, Hofman A, Brayne $\mathrm{C}$ et al. Frequency and distribution of Alzheimer's disease in Europe: a collaborative study of 1980-1990 prevalence findings. The EURODEM-Prevalence Research Group. Ann Neurol. 1991; 30: 381-90.

7. Mathers C, Leonardi M. Global burden of dementia in the year 2000: summary of methods and data sources: World Health Organisation; 2003.

8. Wimo A, Jonsson L, Winblad B. An estimate of the worldwide prevalence and direct costs of dementia in 2003. Dement Geriatr Cogn Disord. 2006; 21: 175-81.

9. Aupperle PM. Navigating patients and caregivers through the course of Alzheimer's disease. J Clin Psychiatry. 2006; 67 Suppl 3: 8-14; quiz 23.

10. Bradford A, Kunik ME, Schulz P et al. Missed and Delayed Diagnosis of Dementia in Primary Care: Prevalence and Contributing Factors. Alzheimer Dis Assoc Disord. 2009; 23: 306-14.

11. Knopman D, Donohue JA, Gutterman EM. Patterns of care in the early stages of Alzheimer's disease: impediments to timely diagnosis. J Am Geriatr Soc. 2000; 48 : 300-4. 
12. Byszewski AM, Molnar FJ, Aminzadeh F et al. Dementia diagnosis disclosure: a study of patient and caregiver perspectives. Alzheimer Dis Assoc Disord. 2007; 21: 107-14.

13. Kurz A, Schulz M, Reed P et al. Personal perspectives of persons with Alzheimer's disease and their carers: a global survey. Alzheimers Dement. 2008; 4: 345-52.

14. Waldemar $G$, Dubois $B$, Emre $M$ et al. Recommendations for the diagnosis and management of Alzheimer's disease and other disorders associated with dementia: EFNS guideline. Eur J Neurol. 2007; 14: e1-26.

15. Bowker M. Assisted dying debate. Life is a terminal condition. Bmj. 2009; 339: b3682.

16. Williams P, Clow S. Genomics, healthcare and public policy. London: Office of Health Economics 1999.

17. Mertes H, Pennings G. Stem cell research policies: who's afraid of complicity? Reprod Biomed Online. 2009; 19 Suppl 1: 38-42.

18. Connell CM, Janevic MR, Gallant MP. The costs of caring: impact of dementia on family caregivers. J Geriatr Psychiatry Neurol. 2001; 14: 179-87.

19. Schulz R, O'Brien A, Czaja $S$ et al. Dementia caregiver intervention research: in search of clinical significance. Gerontologist. 2002; 42: 589-602.

20. AlzheimerEurope. http://www.alzheimer-europe.org; 2009.

21. DeLaGarza VW. Pharmacologic treatment of Alzheimer's disease: an update. Am Fam Physician. 2003; 68: 1365-72.

22. Grossberg GT. Impact of rivastigmine on caregiver burden associated with Alzheimer's disease in both informal care and nursing home settings. Drugs Aging. 2008; 25: 573-84.

23. Lingler $\mathrm{JH}$, Martire LM, Schulz R. Caregiver-specific outcomes in antidementia clinical drug trials: a systematic review and meta-analysis. J Am Geriatr Soc. 2005; 53: $983-90$.

24. Slattum PW, Johnson MA. Caregiver burden in Alzheimer's disease. Consult Pharm. 2004; 19: 352-62. 
25. Sink KM, Covinsky KE, Barnes DE et al. Caregiver characteristics are associated with neuropsychiatric symptoms of dementia. J Am Geriatr Soc. 2006; 54: 796-803.

26. Gineste $Y$, Rosette M. Les liens d'humanitude ou l'art d'être ensemble jusqu'au bout de la vie. In: Soins Corps Communication (http://persowanadoofr/cecformationnet/philohumanitudehtml) 2007.

27. McKhann G, Drachman D, Folstein M et al. Clinical diagnosis of Alzheimer disease: Report of the NINCDS-ADRDA Work Group under the auspices of Department of Health and Human Services Task Force on Alzheimer's disease. Neurology. 1984; 34: $939-44$.

28. McKeith IG, Dickson DW, Lowe J et al. Diagnosis and management of dementia with Lewy bodies: third report of the DLB Consortium. Neurology. 2005; 65: 1863-72.

29. Roman G. Diagnosis of vascular dementia and Alzheimer's disease. Int J Clin Pract Suppl. 2001; 9-13.

30. Sitzer DI, Twamley EW, Jeste DV. Cognitive training in Alzheimer's disease: a metaanalysis of the literature. Acta Psychiatr Scand. 2006; 114: 75-90.

31. Birks J, Grimley Evans J, lakovidou V et al. Rivastigmine for Alzheimer's disease. Cochrane Database Syst Rev. 2009; CD001191.

32. Birks J, Harvey RJ. Donepezil for dementia due to Alzheimer's disease. Cochrane Database Syst Rev. 2006; CD001190.

33. Loy C, Schneider L. Galantamine for Alzheimer's disease and mild cognitive impairment. Cochrane Database Syst Rev. 2006; CD001747.

34. Committee for Medicinal Products for Human Use (CHMP). Guideline on Medicinal Products for the Treatment of Alzheimer's Disease and Other Dementias (Document CPMP/EWP/553/95 Rev 1). London, UK: European Medicines Agency 2009.

35. Vellas B, Andrieu S, Sampaio C et al. Endpoints for trials in Alzheimer's disease: a European task force consensus. Lancet Neurol. 2008; 7: 436-50.

36. Seltzer B, Zolnouni P, Nunez M et al. Efficacy of donepezil in early-stage Alzheimer disease: a randomized placebo-controlled trial. Arch Neurol. 2004; 61: 1852-6. 
37. Farlow M, Anand R, Messina J, Jr. et al. A 52-week study of the efficacy of rivastigmine in patients with mild to moderately severe Alzheimer's disease. Eur Neurol. 2000; 44: 236-41.

38. Grossberg G, Sadowsky C, Förstl H et al. Safety and tolerability of the rivastigmine patch: results of a 28-week open-label extension. Alzheimer Dis Assoc Disord. 2009; 23: $158-64$.

39. Winblad B, Wimo A, Engedal $\mathrm{K}$ et al. 3-year study of donepezil therapy in Alzheimer's disease: effects of early and continuous therapy. Dement Geriatr Cogn Disord. 2006; 21: 353-63.

40. Raskind MA, Peskind ER, Wessel T, Yuan W. Galantamine in AD: A 6-month randomized, placebo-controlled trial with a 6-month extension. The Galantamine USA-1 Study Group. Neurology. 2000; 54: 2261-8.

41. Department of Health. Joint commissioning framework for dementia. Available at: http://www.dh.gov.uk/en/Publicationsandstatistics/Publications/PublicationsPolicyAnd Guidance/DH 100835. Accessed February 262010.

42. Davis $\mathrm{KL}$, Mohs RC, Marin D et al. Cholinergic markers in elderly patients with early signs of Alzheimer disease. JAMA. 1999; 281: 1401-6.

43. Schneider LS, Farlow MR. Severity of AD and response to cholinergic therapy. Eur J Neurol. 1996; 3: 238.

44. Burns A, Spiegel R, Quarg P. Efficacy of rivastigmine in subjects with moderately severe Alzheimer's disease. Int J Geriatr Psychiatry. 2004; 19: 243-9.

45. Poirier J. Evidence that the clinical effects of cholinesterase inhibitors are related to potency and targeting of action. Int J Clin Pract Suppl. 2002; 6-19.

46. Howard RJ, Juszczak E, Ballard CG et al. Donepezil for the treatment of agitation in Alzheimer's disease. N Engl J Med. 2007; 357: 1382-92.

47. Bullock R. Treatment of behavioural and psychiatric symptoms in dementia: implications of recent safety warnings. Curr Med Res Opin. 2005; 21: 1-10. 
48. Verny M, Fremont P, Bourrin JC et al. Reduced psychotropic drug use in patients with Alzheimer's disease receiving rivastigmine: results from the EXELAN study. $J$ Drug Assess. 2004; 7: 123-32.

49. Cummings J, Anand R, Koumaras B, Hartman R. Rivastigmine provides behavioral benefits to Alzheimer's disease patients residing in a nursing home: findings from a 26-week trial. Neurology. 2000; 54:

50. Hogan DB, Goldlist B, Naglie G, Patterson C. Comparison studies of cholinesterase inhibitors for Alzheimer's disease. Lancet Neurol. 2004; 3: 622-6.

51. Raschetti R, Maggini M, Sorrentino GC et al. A cohort study of effectiveness of acetylcholinesterase inhibitors in Alzheimer's disease. Eur J Clin Pharmacol. 2005; 61: $361-8$.

52. Cummings J, Lefèvre G, Small G, Appel-Dingemanse S. Pharmacokinetic rationale for the rivastigmine patch. Neurology. 2007; 69: S10-3.

53. Gauthier S, Emre M, Farlow MR et al. Strategies for continued successful treatment of Alzheimer's disease: switching cholinesterase inhibitors. Curr Med Res Opin. 2003; 19: 707-14.

54. Auriacombe S, Pere JJ, Loria-Kanza Y, Vellas B. Efficacy and safety of rivastigmine in patients with Alzheimer's disease who failed to benefit from treatment with donepezil. Curr Med Res Opin. 2002; 18: 129-38.

55. Tariot PN, Farlow MR, Grossberg GT et al. Memantine treatment in patients with moderate to severe Alzheimer disease already receiving donepezil: a randomized controlled trial. Jama. 2004; 291: 317-24.

56. Singh G, Thomas SK, Arcona S et al. Treatment persistency with rivastigmine and donepezil in a large state medicaid program. J Am Geriatr Soc. 2005; 53: 1269-70.

57. Fratiglioni L, Paillard-Borg S, Winblad B. An active and socially integrated lifestyle in late life might protect against dementia. Lancet Neurol. 2004; 3: 343-53. 
58. Patterson C, Feightner JW, Garcia A et al. Diagnosis and treatment of dementia: 1. Risk assessment and primary prevention of Alzheimer disease. Cmaj. 2008; 178: 548-56.

59. Haag MD, Hofman A, Koudstaal PJ et al. Statins are associated with a reduced risk of Alzheimer disease regardless of lipophilicity. The Rotterdam Study. J Neurol Neurosurg Psychiatry. 2009; 80: 13-7.

60. Estrogen and progestogen therapy in postmenopausal women. Fertil Steril. 2008; 90: S88-102.

61. de Leeuw FE, van Norden AG, van der Flier WM et al. [Alzheimer's disease and treatment of vascular risk factors]. Ned Tijdschr Geneeskd. 2005; 149: 2844-9.

62. van der Beek EM, Kamphuis PJ. The potential role of nutritional components in the management of Alzheimer's Disease. Eur J Pharmacol. 2008; 585: 197-207.

63. Scarmeas N, Luchsinger JA, Mayeux R, Stern Y. Mediterranean diet and Alzheimer disease mortality. Neurology. 2007; 69: 1084-93.

64. Radak Z, Chung HY, Goto S. Systemic adaptation to oxidative challenge induced by regular exercise. Free Radic Biol Med. 2008; 44: 153-9.

65. Clement JP. [Risk factors and protective factors of the insanities]. Morphologie. 2007; 91: 207-20.

66. Kropiunigg U, Sebek K, Leonhardsberger A et al. [Psychosocial risk factors for Alzheimer's disease]. Psychother Psychosom Med Psychol. 1999; 49: 153-9.

67. Ownby RL, Crocco E, Acevedo A et al. Depression and risk for Alzheimer disease: systematic review, meta-analysis, and metaregression analysis. Arch Gen Psychiatry. 2006; 63: 530-8.

68. Living well with dementia: A National Dementia Strategy. Department of Health, Leeds, UK 2009:102.

69. Weinstock M. Selectivity of cholinesterase inhibition. Clinical implications for the treatment of Alzheimer's disease. CNS Drugs. 1999; 12: 307-23. 
70. Grossberg GT, Stahelin HB, Messina JC et al. Lack of adverse pharmacodynamic drug interactions with rivastigmine and twenty-two classes of medications. Int $J$ Geriatr Psychiatry. 2000; 15: 242-7. 


\section{Tables}

Table 1. The six principles of the Alzheimer Disease International (ADI) Global Charter (5)

- Promote awareness and understanding of the disease

- Respect the human rights of the people with the disease

- Recognize the key role of families and carers

- Provide access to health and social care

- Stress the importance of optimal treatment after diagnosis

- Take action to prevent the disease, through improvements in public health 
Table 2. Pharmacological and clinical features of commonly-used symptomatic treatments for Alzheimer's disease $(14,45,69)$.

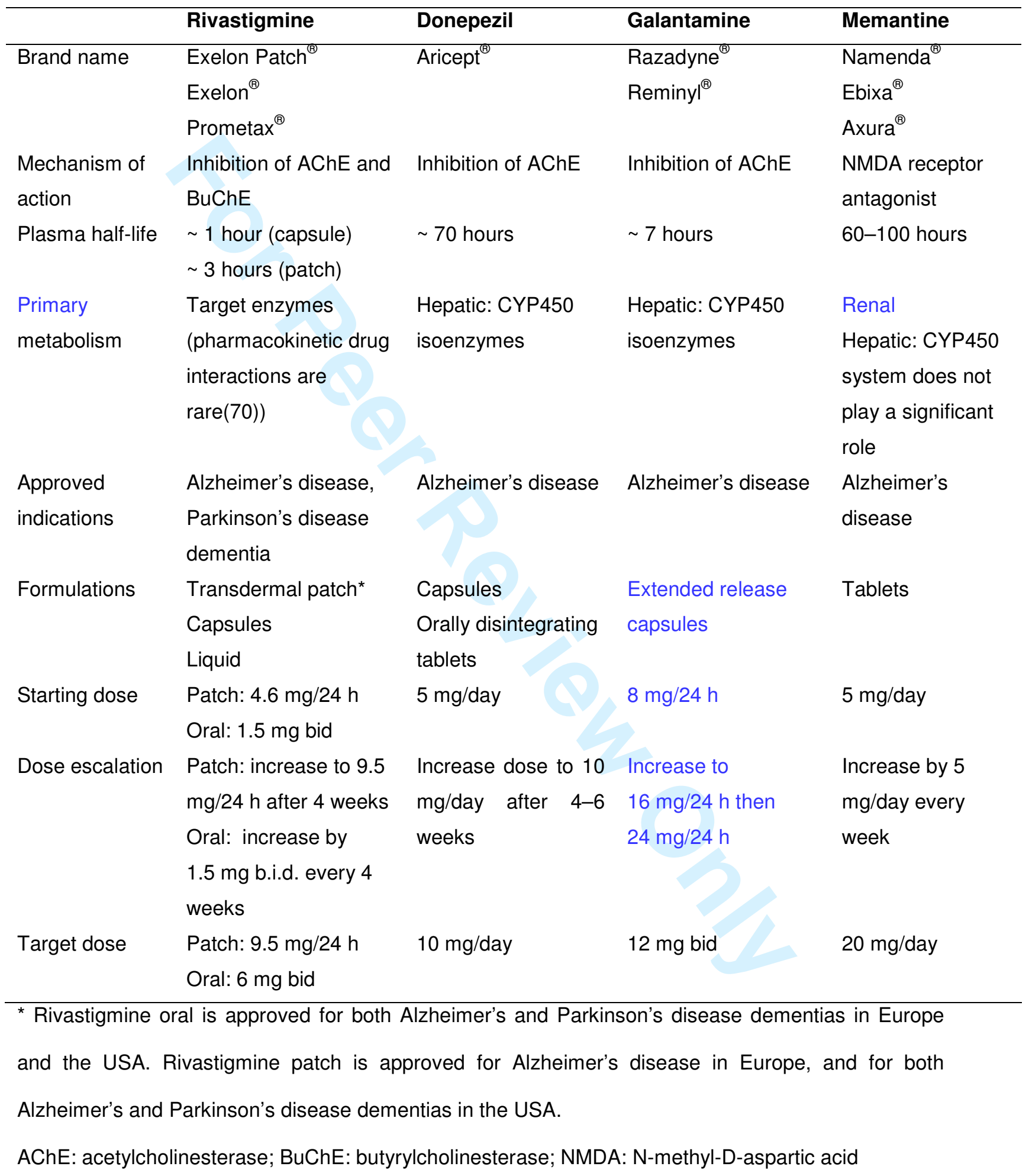


Table 3. Overview of the UK's National Dementia Strategy: joint commissioning of services along a defined care pathway to enable people to live well with dementia (68).

\begin{tabular}{|c|c|c|c|c|}
\hline & Awareness & Diagnosis & Quality of care & Implementation \\
\hline Theme & $\begin{array}{l}\text { Raising awareness } \\
\text { and understanding }\end{array}$ & $\begin{array}{l}\text { Early diagnosis } \\
\text { and support }\end{array}$ & $\begin{array}{l}\text { Living well with } \\
\text { dementia }\end{array}$ & $\begin{array}{l}\text { Making the } \\
\text { change }\end{array}$ \\
\hline 17 objectives & $\begin{array}{l}\text { 1. Public } \\
\text { information } \\
\text { campaign }\end{array}$ & $\begin{array}{l}\text { 2. Memory } \\
\text { services } \\
\text { 3. Information for } \\
\text { patients and } \\
\text { caregivers } \\
\text { 4. Continuity of } \\
\text { support } \\
\text { 5. Peer support }\end{array}$ & $\begin{array}{l}\text { 6. Improved } \\
\text { community } \\
\text { personal } \\
\text { support } \\
\text { 7. Caregivers' } \\
\text { strategy } \\
\text { 8. Improved } \\
\text { hospital care } \\
\text { 9. Improved } \\
\text { intermediate } \\
\text { care } \\
\text { 10. Housing with } \\
\text { telecare } \\
\text { 11. Improved } \\
\text { home care } \\
\text { 12. Improved } \\
\text { end-of-life } \\
\text { care }\end{array}$ & $\begin{array}{l}\text { 13. Workforce } \\
\text { competency, } \\
\text { development } \\
\text { and training } \\
\text { 14. Joint local } \\
\text { commission } \\
\text { strategy } \\
\text { 15. Performance } \\
\text { monitoring } \\
\text { and } \\
\text { evaluation } \\
\text { 16. Research } \\
\text { 17. National and } \\
\text { regional } \\
\text { support for } \\
\text { using this } \\
\text { strategy }\end{array}$ \\
\hline
\end{tabular}




\section{Figure Legends}

Figure 1. Structural MRI in Alzheimer's disease: whole brain atrophy and ventricular enlargement are key features. (Reproduced with the kind permission of Dr Pablo Martínez Lage, Fundacion ACE, Barcelona, Spain).

Figure 2. Functional imaging (SPECT) showing bilateral temporal, parietal and posterior cingular hypoperfusion in a 76-year-old patient with mild Alzheimer's disease. (Reproduced with the kind permission of Drs P Martínez-Lage and I Roca, Fundacion ACE, Barcelona, Spain).

Figure 3. Functional imaging (FDG-PET) in Alzheimer's disease: bilateral temperoparietal hypometabolism. (Reproduced with the kind permission of Drs P Martinez-Lage and J Arbizu, Fundacion ACE, Barcelona, Spain). 


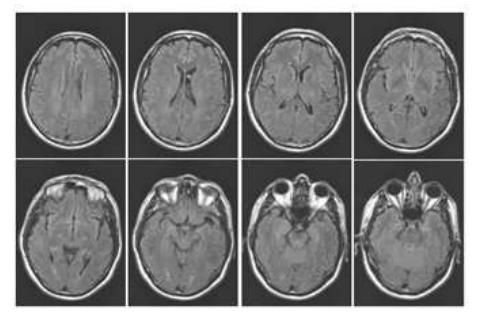

Control subject

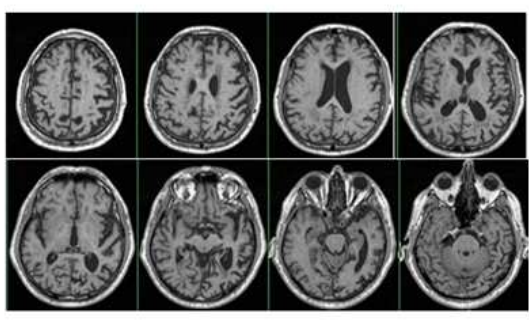

AD patient

Figure 1. Structural MRI in Alzheimer's disease: whole brain atrophy and ventricular enlargement are key features. (Reproduced with the kind permission of Dr Pablo Martínez Lage, Fundacion ACE, Barcelona, Spain).

$254 \times 190 \mathrm{~mm}(96 \times 96$ DPI) 
Figure 2. Functional imaging (SPECT) showing bilateral temporal, parietal and posterior cingular hypoperfusion in a 76-year-old patient with mild Alzheimer's disease. (Reproduced with the kind permission of Drs P Martínez-Lage and I Roca, Fundacion ACE, Barcelona, Spain). $254 \times 190 \mathrm{~mm}(96 \times 96 \mathrm{DPI})$ 

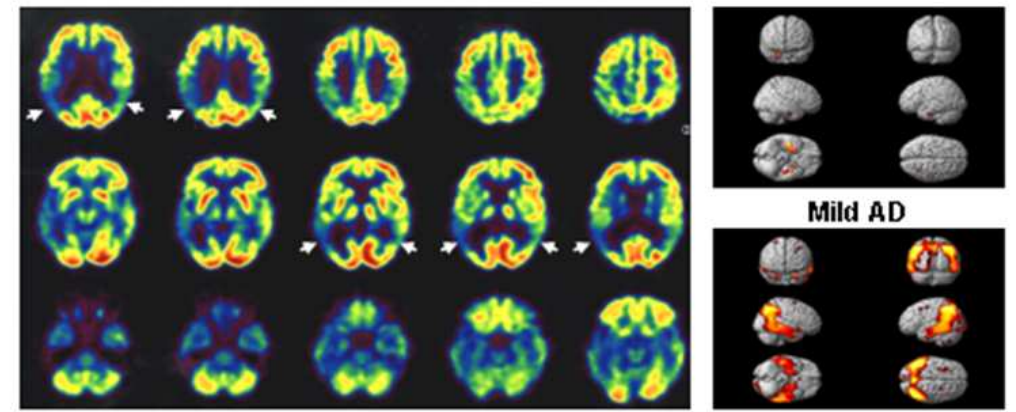

Mild AD

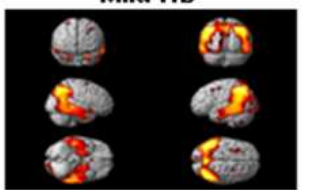

Moderate AD

Figure 3. Functional imaging (FDG-PET) in Alzheimer's disease: bilateral temperoparietal hypometabolism. (Reproduced with the kind permission of Drs P Martinez-Lage and J Arbizu, Fundacion ACE, Barcelona, Spain). 254x190mm (96 x 96 DPI) 